\title{
PMIIDAS: Integration of Open Educational Resources Based on Semantic Technologies
}

\author{
Cristal Karina Galindoํㅜ, R. Carolina Medina-Ramírez¹, María Auxilio Medina², \\ José Luis García-Cué ${ }^{3}$ \\ ${ }^{1}$ Universidad Autónoma Metropolitana, Department of Electric Engineering, \\ Iztapalapa, Mexico \\ ${ }^{2}$ Universidad Politécnica de Puebla, Department of Posgraduate, Mexico \\ ${ }^{3}$ Colegio de Postgraduados, Campus Montecillo, Texcoco, Mexico \\ cdgalindod@gmail.com, cmed@xanum.uam.mx, \\ mauxmedina@gmail.com, jlgcuedcolpos.mx
}

\begin{abstract}
This article presents a prototype called PMIIDAS. The prototype focuses on the creation of open educational resources based on pedagogical and institutional guidelines, their representation using semantic indexing, and the storage and retrieval thereof by Semantic Web technologies. The use of this prototype can have benefits such as the reuse of open educational resources, which are distributed in institutional repositories or educational platforms by applying a semantic approach, search and retrieval of relevant information can be done through the use of ontologies and user profiles; as well as the exchange of educational resources among educational institutions.
\end{abstract}

Keywords. Applications, education, open educational, semantic web, ontology.

\section{Introduction}

By the Budapest open access initiatives [1], Bethesda [2] and Berlin [3] worldwide have motivated the creation of technological platforms such as the Institutional Repositories (IR), which are implemented in a wide variety of universities and research centers in order to be able to disseminate, share and transfer scientific and academic production, which is embodied in different educational resources. IRs can be considered as institutional memories preserving and increasing knowledge embodied in educational resources [4].

An IR can be understood as an information system that collects, preserves, disseminates and gives access to the scientific and intellectual production of an educational or scientific institution. In addition to having mechanisms to store, preserve and recover educational resources [5] [6]. These educational resources are described through metadata, which conforms to the standard OAI-PMH (Open Archives Initia- 
tive Protocol for Metadata Harvesting) [7], which is implemented as a protocol for interoperability in different IRs such as DSpace [8] E-Prints [9], Opus [10], etc.

On the other hand, the educational resources contained in the IRs when adopting open access policies become open educational resources. The United Nations Organization for Education, Science and Culture [11] defines an Open Educational Resource (OER) as any teaching, learning or research material which is in the public domain or which has been published under an intellectual property license that allows its use, adaptation and free distribution.

The opening of resources refers not only to free access to query them, to enrich them or to generate new resources from the original resources, but also to an open structure (semantic indexing) in a processable format (RDF, Resource Description Framework) [12]. Semantic Web technologies are made up of ontologies, descriptions of resources (semantic indexes) and languages for managing and representing of knowledge. The use of these technologies makes it possible to dynamically and actively reach the user by stimulating the use of applications and achieving a shorter time in the search for open educational resources [13].

This article presents the Prototype PMIIDAS, which is the acronym for Integrating Memory of Documentary Information Sources for Educational Institutions Based on Semantic Web Technologies; such tool can be defined as an organizational memory for educational purposes. The knowledge possessed by people (professors, learners and officers) and by educational resources (which are heterogeneous in content, format and type) is materialized explicitly and persistently in this tool in order to contribute to their reuse and decision making among members of the educational institution [12].

This prototype can be seen as a proposal to concentrate OERs within an educational institution, but also as an integration tool for different educational platforms. This prototype focuses on the creation of OERs based on institutional and educational guidelines, their representation using semantic indexing, and the storage and retrieval thereof by Semantic Web technologies.

The rest of the article is structured as follows: 1) Section II presents a review of the works related to education based on semantic Web technologies, as well as the institutional repositories that have emerged; 2) Section III discusses the methodology and the different stages, as well as the different activities that were used in the proposed work; 3) Section IV shows the process used for prototype design; 4) Section V shows the different tests on the queries made to the ontologies and the tests carried out on the prototype; and finally 5) Section VI shows the conclusion.

\section{Related Work}

In this section we present the description of some works that have been carried out in education and that use the semantic approach; as well as institutional repositories.

One of the main works in education based on the semantic approach is the ELENA project [14], which is a European Community project whose primary objective is to allow the creation of a "Smart Learning Space" by standards, educational mediators 
and semantic Web technologies as key factors in the integration of e-learning educational resources.

The article titled "A computational model for developing semantic web-based educational systems" [15] presents a computational model for the development of Webbased Semantic Educational Prototypes, focusing on adaptive learning.

The Didactalia project [16] proposes a personal learning environment including semantic and social tools, having a space in which the user collects show and share learning contents.

Procomún [17] is an intelligent, social and distributed Web, which is part of an educational environment under the building. Such tool can connect with educational communities in existing spaces by the Linked Open Data Cloud [18] using its semantic properties.

The work of Medina et al. [19] proposes a strategy to produce and consume linked open data from the OAI-PMH protocol, which is compatible with repositories.

As for the institutional repositories, we highlight the educational work called the Mexican Network of Institutional Repositories (REMERI by the acronym in Spanish), which emerged in 2012 with the purpose of integrating, spreading, preserving and giving visibility to the scientific, educational and documentary production of Mexico [20]. It is also the national network representing Mexico in the Federated Network of Institutional Repositories of Scientific Publications or LA REFERENCIA project where nine Latin American countries (Argentina, Brazil, Costa Rica, Chile, Colombia, Ecuador, El Salvador, Mexico and Peru) participate [21].

Also, the proposed law to create the national repository was approved during 2014 in Mexico. This proposed law is governed by the National Council on Science and Technology (CONACyT by the acronym in Spanish) and aims to make available the scientific and educational resources produced in Mexico with public funds [22].

In general, educational work based on semantic approach has examined proposals to exploit the Semantic Web approach from different perspectives. However, it is worth noting that there is little work developed in the establishment of educational guidelines to guide the process of creating OERs in the area of exercises, practices, thematic presentations, among others; since mainly OERs focus on the dissemination of theses, books and chapters of books, articles, etc., leaving aside teaching materials [23], and such materials represent the knowledge and experience that Professors have within the Institutions. On the other hand, an educational ontology that models education in the Mexican context has not been created. Besides, the data to describe OERs only include bibliographic metadata based mainly on the Dublin Core standard [24], without taking advantage of the content data and links to the resource itself.

\section{$3 \quad$ Applied Methodology}

The research presented is composed of two stages, these are: a) detection of needs by the study of use and preferences of Information and Communication Technologies (ICT) in the educational field, and b) building of the Prototype PMIIDAS. 


\subsection{Detection of Needs}

At this stage, a study was carried out on the use of Information and Communication Technologies (ICT) to Professors and Learners of two higher education institutions. This study was applied to the curricula of Degree in Computing and the Degree in Electronics Engineering; as well as the Postgraduate in Information Science and Technology (master's and doctorate) attached to the Universidad Autónoma Metropolitana, Iztapalapa (UAM-I). Also, such study was applied on the Military Computing and Military Communications and Electronics Engineering of the Military School of Engineers (EMI by the acronym in Spanish).

From the analysis made to the study, user profiles, educational resources frequently used by Professors, educational resources of interest, and subjects requiring open educational resources could be determined. Using the information gathered from the study, we can propose the building of the prototype according to the needs expressed by the professors and learners of the two institutions.

\subsection{Building of the Prototype MIIDAS}

At this stage, different activities to be performed were established to develop the prototype, these are: a) Definition of the guidelines for generating educational resources; b) Building of the domain ontologies; c) Design of the prototype architecture, and d) Implementation of the prototype.

The following describes in detail each of the activities.

Definition of the guidelines for generating educational resources. In order to establish the guidelines for educational resources, the resources of greatest interest identified in the needs detection stage performed in both institutions were taken into account, which are: exercises, practices and thematic presentations.

Table 1. Common criteria for exercises, practices and thematic presentations (Source: own research).

\begin{tabular}{|c|c|}
\hline Common criteria & Description \\
\hline Educational Institution & $\begin{array}{l}\text { Corresponds to the name of the educational institution to which } \\
\text { the resource's author is attached. }\end{array}$ \\
\hline Facilitator's Name & Name of the person who serves as the course instructor. \\
\hline Name of Study Program & $\begin{array}{l}\text { Name of the degree, engineering or postgraduate to which the resource } \\
\text { impacts }\end{array}$ \\
\hline Suggested Period of Use & Year, semester, quarter or quarter to which the resource can be applied. \\
\hline Learning Unit & Name of the subject or subject for which the resource is designed. \\
\hline Unit of Competence & Refers to one of the topics that are part of the Learning Unit. \\
\hline Element of Competence & It is aimed at achieving the objective of the ongoing unit of competence. \\
\hline
\end{tabular}

Once the resources of greatest interest were identified, the educational approaches used by both educational institutions were explored, which was the competency-based 
approach. This approach is characterized by the identification of knowledge, expertise, skills, attitudes and values required to carry out a task [25].

The guidelines were worked together with specialists in pedagogy and didactics, by criteria that obey the competence approach. The common structure criteria among the three educational resources are presented in table 1 .

It is important to point out that guidelines within institutions can help to standardize the educational resources created within the institution, as well as guiding new professors who are incorporated to generate their educational resources.

Building of the domain ontologies. Ontologies are a fundamental part of the Semantic Web Approach and therefore also for the Prototype PMIIDAS, since they provide a formal and standard representation of knowledge through a common vocabulary, favoring the exchange of such knowledge and its reuse among applications.

From the analysis carried out in the needs detection stage, 6 ontologies could be identified for the Prototype PMIIDAS. These are: user profile, domain (Computer, Electronic and Military), educational and digital educational resources. These ontologies have as main objective to establish a useful conceptual vocabulary for the project, as well as represent the concepts and relations inherent in the knowledge domain, thus constituting a knowledge model that allows us to make inferences about the data.

Methodology 101 [26] was adopted for building the ontologies. Such methodology was proposed by Stanford University and consists of 7 phases, which are: 1) Determine the domain and scope of the ontology; 2) Reuse existing ontologies; 3) List important terms for the ontology; 4) Define classes and their hierarchy; 5) Define the properties of the classes: slots, 6) Define the facets of the slots; and 7) Create instances or individuals. Table 2 shows the competence questions and the process to be performed for the user profile ontology.

Table 2. Competence questions and process to be performed for the user profile ontology (Source: own research).

Competence questions

Process to be performed

What professional activities do the professors and learners do?

What skills do the professors and learners have?

In what subjects are the professors specialized?

What are the learners advised by professors?

Who are the learners of a particular professor?

Adaptation of the user profile ontology proposed in [20] and

What are the learners with a particular English reading domain and inter-

the person ontology [11].

est in Semantic Web research?

Table 3 and 4 show the competency questions and the process to be performed for the ontology of digital educational resources and the educational ontology, respectively.

The subjects requiring educational resources identified in the stage of needs detection were taken up again in order to determine the subjects and competency questions of the ontologies for computing and electronics. Table 5 shows the subject names identified by institution and user. 
Cristal Karina Galindo Durán, R.Carolina Medina-Ramírez, María Auxilio Medina Nieto, et al.

Table 3. Competence questions and process to be performed for the ontology of educational resources (Source: own research).

\begin{tabular}{ll}
\hline \multicolumn{1}{c}{ Competence questions } & Process to be performed \\
\hline What kind of educational resources are favorable for the active learning? & \\
What kind of educational resources are suggested for the subject of Database? & Adaptation of the ontolo- \\
What are the educational resources that have pdf extension? & gy proposed in [11]. \\
What are the English language resources for Electronics? & \\
\hline
\end{tabular}

Table 4. Competence questions and process to be performed for educational ontology (Source: own research).

\begin{tabular}{ll}
\hline \multicolumn{1}{c}{ Competence questions } & Process to be performed \\
\hline What kind of educational approach do UAMI and EMI use? & \\
What are the teaching strategies established in the UAMI and the EMI? & The building of the ontology \\
What educational resources can be used to support specific teaching strategies? & with a support of domain \\
What teaching strategies can help achieve the analysis? & experts. \\
What are the assessment tools used by EMI? & \\
\hline
\end{tabular}

Table 5. Subjects requiring educational resources for UAM-I and EMI learners and professors (Source: own research).

\begin{tabular}{ccc}
\hline User & UAM-I & EMI \\
\hline & Subject & \\
& Introduction to Programming & Electronics \\
Learners & Programming Fundamentals & Programming \\
& Data Structures and Algorithms & Digital Systems \\
& & Microcontrollers \\
& Introduction to Programming & \\
Professors & Computer Networks & Programming \\
& Digital Communications & Electronics \\
& Databases & Microcontrollers \\
\hline
\end{tabular}

Based on the identified subjects and the content analysis of each one, the competence questions are proposed for domain ontology for Computing and Electronics. Table 6 shows some of the competency questions and the activity to be performed.

In general, all the ontologies of the Prototype PMIIDAS have a total of 1,162 concepts distributed as follows: 22 concepts of user profile ontology; 30 concepts of the ontology for digital educational resources; 22 concepts of the Educational Ontology; and 804 concepts of the different domain ontologies distributed as follows: 662 concepts of computing; 142 concepts of Electronics; and 284 concepts of military ontology.

All the ontologies were developed with the ontology editor Protégé. On the other hand, it is important to point out that all ontologies have been validated by experts in 
each of the domains, as well as by the reasoner Pellet in order to verify the possible inconsistencies that could be found in them.

Table 6. Competence questions and process to be performed for ontologies for Computing, Electronics and Military (Source: own research).

\begin{tabular}{|c|c|c|}
\hline Ontology & Competence question & Process to be performed \\
\hline Computing & $\begin{array}{l}\text { Is the star topology a network topology? } \\
\text { Is the integer a primitive data type? } \\
\text { Is analysis one of the stages in creating soft- } \\
\text { ware? }\end{array}$ & $\begin{array}{l}\text { Adaptation of the Ontology } \\
\text { proposed in [4] }\end{array}$ \\
\hline Electronics & $\begin{array}{l}\text { What are the families of integrated circuits? } \\
\text { What are the types of diodes? } \\
\text { What are the parts of a transistor? }\end{array}$ & $\begin{array}{l}\text { Adaptation of the Ontology } \\
\text { proposed in [4] }\end{array}$ \\
\hline Military & $\begin{array}{l}\text { What is a council of war? } \\
\text { What are the sub-values promoted by the Mili- } \\
\text { tary Education System? } \\
\text { What is a duty in the military field? }\end{array}$ & $\begin{array}{l}\text { Building of the Ontology } \\
\text { with the support of military } \\
\text { personnel }\end{array}$ \\
\hline
\end{tabular}

Table 7. Use cases, description, user, and priority for the Prototype PMIIDAS (Source: own research).

\begin{tabular}{|c|c|c|c|}
\hline User Case & Description & User & Priority \\
\hline UC1-Login & Allows to $\log$ in to the prototype & $\begin{array}{l}\text { Professor, learn- } \\
\text { er and assess- } \\
\text { ment committee }\end{array}$ & Half \\
\hline UC2-Register user & Records the data of a new user & $\begin{array}{l}\text { Professor, learn- } \\
\text { er and assess- } \\
\text { ment committee }\end{array}$ & Half \\
\hline UC3-Generate OER & $\begin{array}{l}\text { Creates OERs in digital form - exercise } \\
\text { and practice type }\end{array}$ & Professor & High \\
\hline UC4-Modify OER & $\begin{array}{l}\text { Modify, delete and visualize the generat- } \\
\text { ed OERs }\end{array}$ & Professor & High \\
\hline UC5-Load OER & $\begin{array}{l}\text { Allows to load the OER into the IR, } \\
\text { creating its semantic indexing }\end{array}$ & Professor & High \\
\hline UC6-Recovering OER & Query and/or search for an OER & $\begin{array}{l}\text { Professor, learn- } \\
\text { er and assess- } \\
\text { ment committee }\end{array}$ & High \\
\hline UC7-Query guidelines & $\begin{array}{l}\text { Shows the guidelines for the creation and } \\
\text { use of OERs; as well as the prototype. }\end{array}$ & $\begin{array}{l}\text { Professor, learn- } \\
\text { er and assess- } \\
\text { ment committee }\end{array}$ & Low \\
\hline
\end{tabular}

Prototype Design: Modeling is a central part of all the activities that lead to the production of good software. To carry out the requirements and architecture design activities for the Prototype PMIIDAS was based on the software architecture [27], 
where we used mainly the diagrams of 1) use cases and 2) architecture. The use of each is detailed below.

Use Case Diagram: These diagrams define the activities that the different users (professor, learner and assessment committee) will have in the prototype. The use cases, their description, the types of users, and the priority of each of them are showed in table 7.

Architecture Diagram: The type of architecture chosen for the creation of the Prototype PMIIDAS is a Web architecture due to the study carried out at EMI and UAMI which considers the following reasons:

Users targeted by the prototype prefer to use web applications to query educational resources. In addition, they frequently use the computer for reviewing such resources.

Applications developed using a web architecture are lighter because they do not consume client resources, since the presentation, business and data layers are controlled by the server.

Fig. 1 shows the Architecture diagram of the Prototype PMIIDAS and different components thereof and the table 8 shows the description of the components of the Prototype PMIIDAS.

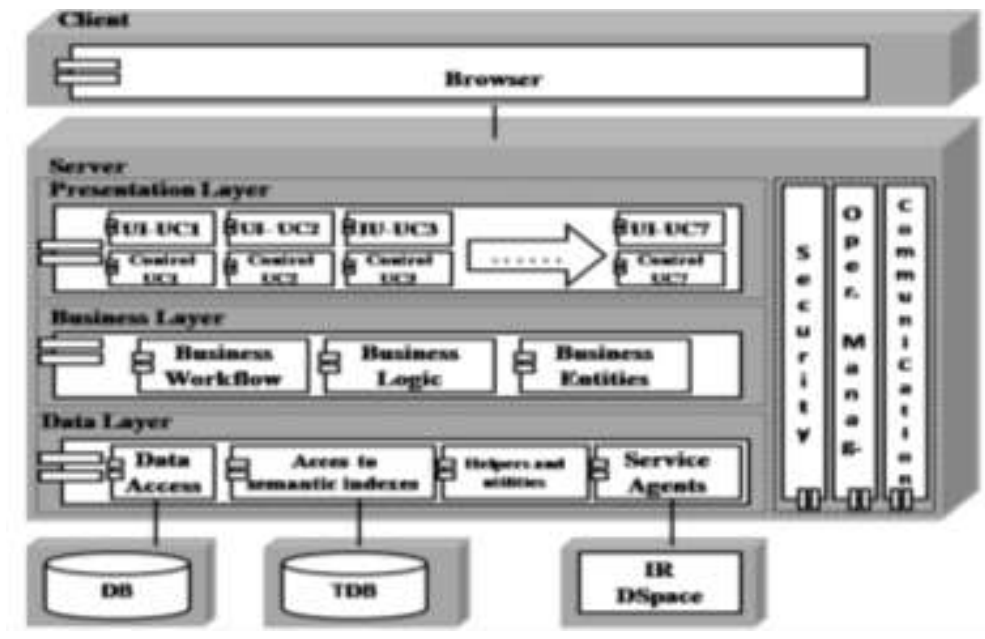

Fig.1. Architecture diagram of the Prototype PMIIDAS (notation: UML, Source: own research).

On the other hand, the Prototype PMIIDAS can also be seen as an integrator of different platforms, since it can superimpose a semantic layer where educational resources can be contained in multiple sites and be queried and retrieved by such prototype. Fig. 2 shows this concept, where a user makes a request for a resource, which is found on some platform, by a graphical interface. The Prototype PMIIDAS processes such request and together the semantic indexes know the location of this through the Unique Resource Identifier (URI). On the other hand, the Prototype PMIIDAS can consume the resources contained in the platforms provided there is a service provider [28]. 
Table 8. Description of the components that make up the architecture of the Prototype MIIDAS (Source: own research).

\begin{tabular}{|c|c|}
\hline Component & $\begin{array}{c}\text { Description } \\
\end{array}$ \\
\hline Browser & It is the application running on the client machine \\
\hline UI-UC & It is the graphical interface in charge of the user interaction \\
\hline UC Control & $\begin{array}{l}\text { They are the components in charge of validations, business logics; as } \\
\text { well as providing the data to the business layer }\end{array}$ \\
\hline Workflow & It is the component in charge of managing the business processes \\
\hline Business Logic & $\begin{array}{l}\text { It is the component responsible for retrieving and processing data ac- } \\
\text { cording to business logics }\end{array}$ \\
\hline Business Entities & $\begin{array}{l}\text { This component represents the business domain entities and their asso- } \\
\text { ciation with the business logic component }\end{array}$ \\
\hline Access To Data & This component provides mechanisms to persist and retrieve data \\
\hline $\begin{array}{l}\text { Access To Semantic } \\
\text { Indexes }\end{array}$ & $\begin{array}{l}\text { This component is responsible for interacting with the Triple Store } \\
\text { (TDB) to save and query the semantic indexes that characterize the } \\
\text { resources }\end{array}$ \\
\hline Tools and Utilities & $\begin{array}{l}\text { This module contains functionality common with other modules such } \\
\text { as: casting data types, e-mail sending, language coding, among others. }\end{array}$ \\
\hline Service Agents & $\begin{array}{l}\text { This module is responsible for the communication mechanisms to trans- } \\
\text { fer data and resources to the institutional repository, such as DSpace }\end{array}$ \\
\hline Security & Component responsible for authorization and authentication \\
\hline Operation Management & $\begin{array}{l}\text { This module handles exception management, instrumentation and vali- } \\
\text { dation }\end{array}$ \\
\hline Communication & $\begin{array}{l}\text { This module provides communication between the upper layers and } \\
\text { physical levels }\end{array}$ \\
\hline
\end{tabular}

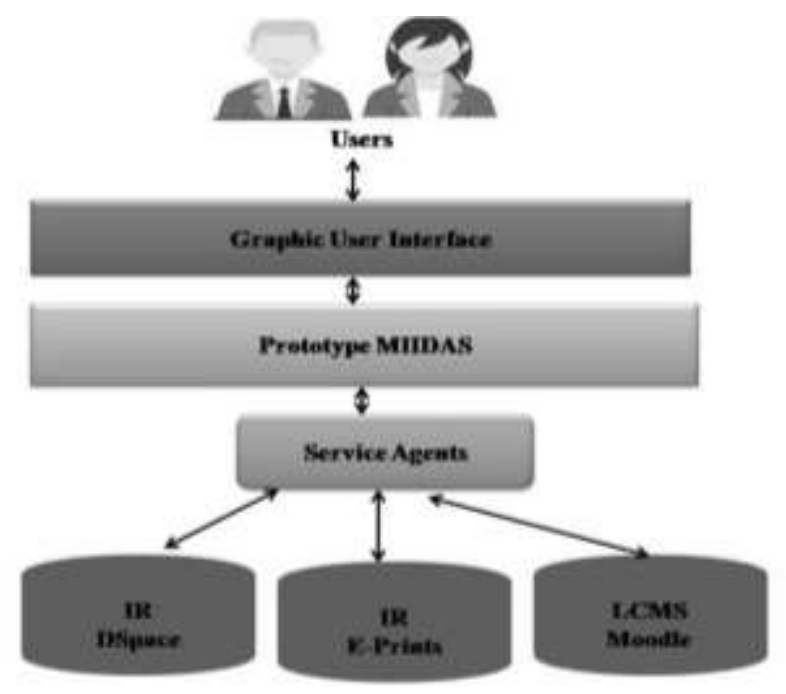

Fig. 2. Prototype PMIIDAS as integrator of different platforms (Source: own research). 
Implementation. The building of the Prototype PMIIDAS is based on from analysis, design programming, data storage, educational resources and representation by semantic indexing free software languages and tools.

The prototype was developed in the Java programming language using the Apache Tomcat application server, as PostgreSQL Database Management System Version 9.4, Apache Jena Version 3.4 and DSpace Version 6.0. Fig. 3 shows the different technologies used to create the prototype.

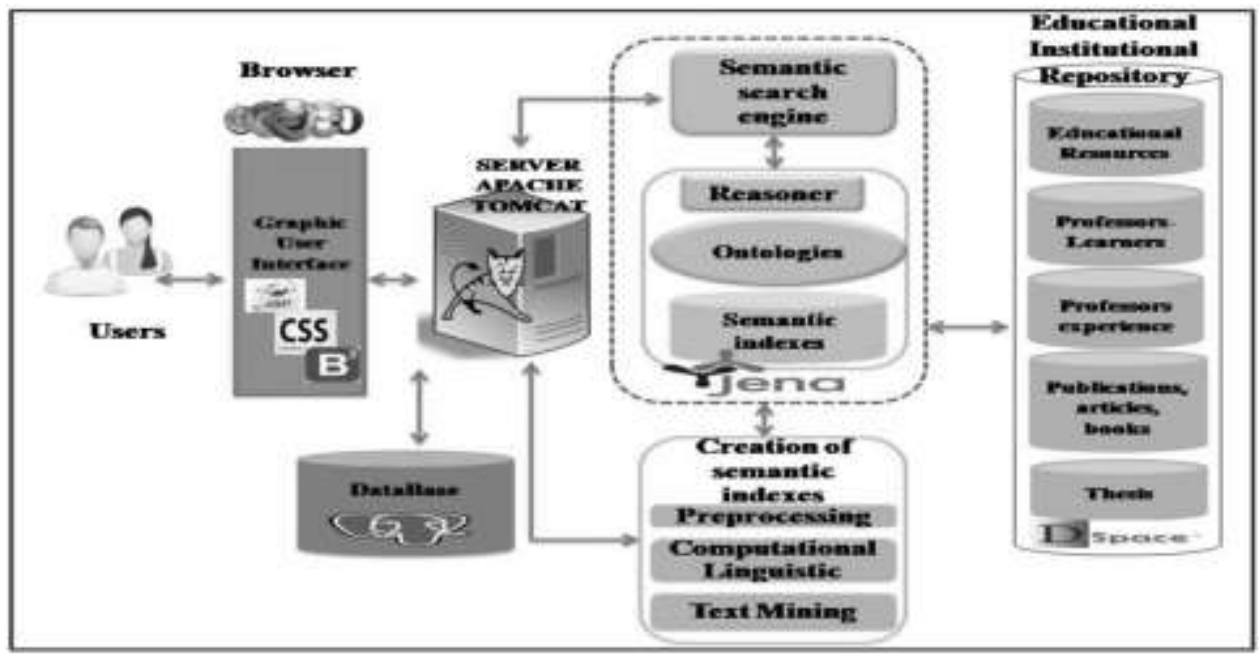

Fig. 3. Technologies used in the development of the Prototype PMIIDAS (Source: own research).

Where:

Interface. Allows communication between users and the system, is responsible for providing a visual environment to perform the different activities provided by the prototype according to the role of each user.

Apache Tomcat Server. Attends user requests from a graphical interface and answers according to the request.

Database. Conformed by user data and catalogues used in the creation of educational resources.

Semantic Search Engine. Recovers educational resources according to the search made by the use with the help of ontologies and semantic indexes.

Ontologies. Establishes the conceptual vocabulary of a field of knowledge (user profile, educational and domain resources: Computing, Military and Electronics) through concepts and relations thereof by constituting a model knowledge, which allows making inferences about the semantic indexing for educational resources.

Semantic Indexing (SMSI). Describes the educational resources made up of three parts: 1) metadata, 2) contents, and 3) links to others OERs.

Creation of SMSI. Creates the semantic indexing that describes each of the educational resources in Resource Description Framework (RDF), which are stored in the 
Triple Store (TDB). The creation of semantic indexes is an automatic process, where the metadata is obtained from the form that fills the user to upload the file; to obtain the content and links of the same one is realized a preprocessing, to apply techniques of computational linguistics; as well as text mining.

Institutional Educational Repository: In charge of storing educational resources generated by professors in different formats and contents.

The prototype was developed under the usability quality attribute, which is to be friendly, intuitive and straightforward in navigation.

\section{Experiments}

The experiments carried out have been focused on testing the ontologies and the prototype.

\subsection{Ontologies Testing}

In general, the tests performed on the ontologies consisted of entering individuals and interrogating them using the competency questions initially made.

Table 9 shows the questions asked to the user profile ontology; as well as its translation in SPARQL query language and its result.

Table 9. Example of queries to the user profile ontology (Source: own research).

\begin{tabular}{|c|c|c|}
\hline $\begin{array}{c}\text { Natural Language } \\
\text { Query }\end{array}$ & Query in SPARQL & Result \\
\hline $\begin{array}{l}\text { Who does Carolina } \\
\text { Medina advise? }\end{array}$ & $\begin{array}{l}\text { PREFIXopu: } \\
\text { <http://pcyti.izt.uam.mx/pmiidas/ontoperfilusuario\#> } \\
\text { SELECT ?discente } \\
\quad \text { WHERE \{ } \\
\text { ?docente opu:asesoraA ?discente. } \\
\text { FILTER regex(?docente, "^Carolina Medina" ).\} }\end{array}$ & $\begin{array}{l}\text { Cristal Galin- } \\
\text { do, Pablo } \\
\text { Contreras }\end{array}$ \\
\hline $\begin{array}{l}\text { Who is an expert in } \\
\text { Semantic Web? }\end{array}$ & $\begin{array}{l}\text { SELECT ?docente } \\
\text { WHERE \{ } \\
\text { ?docente opu:esExpertoEn ?tema. } \\
\text { FILTER regex(?tema, "web_semantica", "i" ). \} }\end{array}$ & $\begin{array}{l}\text { Carolina Me- } \\
\text { dina, Ma- } \\
\text { ríaAuxilio } \\
\text { Medina }\end{array}$ \\
\hline
\end{tabular}

Table 10 shows the questions asked to the ontology for digital educational resources. Table 11 shows the questions asked to the educational ontology.

\subsection{Prototype Testing}

The tests carried out on the Prototype PMIIDAS that have been made are: unitary and integration; As well as configuration. Each of them is detailed below. 
Cristal Karina Galindo Durán, R.Carolina Medina-Ramírez, María Auxilio Medina Nieto, et al.

Table 10. Example of queries to the ontology for digital educational resources (Source: own research).

\begin{tabular}{|c|c|c|}
\hline $\begin{array}{c}\text { Natural Language } \\
\text { Query }\end{array}$ & Query in SPARQL & Result \\
\hline $\begin{array}{l}\text { What are the digital } \\
\text { educational re- } \\
\text { sources produced by } \\
\text { UAMI? }\end{array}$ & $\begin{array}{l}\text { PREFIX ored: } \\
\text { http://pcyti.izt.uam.mx/pmiidas/ontored\# } \\
\text { SELECT ?recursosWHERE \{ } \\
\text { ?recursosored:esProducidoPor ?universidades. }\}\end{array}$ & $\begin{array}{l}\text { Exercise } 1 \\
\text { Practice } 5 \\
\text { PresentationBD }\end{array}$ \\
\hline $\begin{array}{l}\text { What is the topic of } \\
\text { Exercise } 1 ?\end{array}$ & $\begin{array}{l}\text { SELECT ?temaWHERE \{ } \\
\quad \text { ?recurso ored:tieneTema ?tema. } \\
\text { FILTER regex (?recurso, "^Ejercicio1"). }\end{array}$ & Programming \\
\hline
\end{tabular}

Table 11. Example of queries to the educational ontology (Source: own research).

\begin{tabular}{lll}
\hline Natural Language Query & Query in SPARQL & Result \\
\hline & PREFIXoed: & \\
To which educational & <http://pcyti.izt.uam.mx/pmiidas/ontoeduca\#> & SELECT ?ies WHERE \{ \\
institution belongs the & ?PEstudiooed:perteneceA ?ies. & UAMI \\
Degree in Computing? & FILTERregex (?PEstudio, "^Licenciatura en Computacion"). & \\
& & \\
To which model belongs & SELECT ?modelo & WHERE \{ \\
the auditory learning & ?eaoed:perteneceAModelo ?modelo. & VAK \\
style? & FILTER regex (?ea, "Auditivo", "i"). $\}$ & \\
\hline
\end{tabular}

Unit and integration testing. Each module has been tested separately to verify the correct operation of the prototype. For this, test cases with repeatable, complete, reusable and independent characteristics were established.

On the other hand, the interaction among the different modules was verified. This test is known as an integration test.

Configuration testing. To discover specific bugs or compatibility issues in a particular environment, the prototype was tested in three Web browsers (Mozilla Firefox, Google Chrome, and Internet Explorer) with the intention of ensuring that the user experience is the same in all of them. Table 12 shows the bugs identified for each browser.

Table 12. Configuration test results (Source: own research).

\begin{tabular}{ll}
\hline \multicolumn{1}{c}{ Web Browser } & \multicolumn{1}{c}{ Identified failures } \\
\hline Internet Explorer & $\begin{array}{l}\text { The logo of the Prototype PMIIDAS in the header is traversed to the left } \\
\text { The input help text does not appear }\end{array}$ \\
Google Chrome & $\begin{array}{l}\text { Pop-up windows are not displayed } \\
\text { Calendars do not display } \\
\text { Mozilla }\end{array}$ \\
\end{tabular}


Regarding the usability of the Prototype PMIIDAS, an assessment tool (rubric) has been designed to evaluate educational software, which is based on [29] and [30]. This rubric is made up of 5 different sections, which are: 1) structure and display, 2) efficiency, 3) usability, 4) quality, and 5) pedagogical dimension. The first section aims to know the structure of the information in conjunction with the graphic elements. The second section seeks to understand the ease in which the users perform the tasks. The third section is intended to facilitate the interaction of the prototype with the user without having to consult the manual. The fourth section aims to know the accuracy of information retrieval. Finally, the fifth section seeks to know the specific characteristics to contribute to the teaching-learning process performed by the prototype.

The rating scale for each of the criteria is from 1 to 5 , with 1 being the lowest rating and 5 being the highest rating.

\section{Conclusions}

This article has shown the methodology, design and implementation of the Prototype PMIIDAS, which allows the creation, edition, management and reuse of open educational resources that can be part of an institutional repository or any other platform. This is because it superimposes a semantic layer where each resource is characterized by a semantic index in RDF format and that point to the physical location of the resource.

This prototype was designed using the guidelines established by the software architecture and using the spiral model, because of this it was necessary to make different modifications at the level of the proposed design, the relational model, and the structure of the semantic index and technologies planned at the beginning of the process. The application offers the possibility to characterize different types of resources in other domains. Therefore, the prototype can be seen as a generic application to integrate resources in any domain. For which, it is only necessary to incorporate the ontologies according to the particular domain so that their applications and uses can be very diverse.

In addition, it is proposed the total implementation of the educational ontology which models education in the Mexican context, this to build applications that help in the preparation of primary and higher-level Professors to make the knowledge exam stipulated for the Professor assessment established by the National Institute for the Assessment of Education (INEE by the acronym in Spanish). On the other hand, it is suggested to perform tests with other institutional repositories other than DSpace; as well as the characterization of educational resources contained in Learning Content Management Platforms such as Moodle.

Acknowledgement. The authors would like to thank MS Laura Avilés Ortiz for her invaluable knowledge in Pedagogy, which was fundamental to build the educational ontology, Dr. Humberto Cervantes for his support and guidance in the architecture development of the Prototype PMIIDAS. 


\section{References}

1. Budapest Open Access Initiative, http://www.budapestopenaccessinitiative.org/ (2017)

2. Bethesda Statement on Open Access Publishing, http://legacy.earlham.edu/ $\sim$ peters/fos/bethesda.htm (2017)

3. Berlin Declaration, https://openaccess.mpg.de/Berlin-Declaration (2017)

4. Álvarez Terrazas, J., Álvarez Terrazas, M., Gallegos Cereceres, V., Polanco Rodríguez, I.: La importancia de los repositorios institucionales para la educación y la investigación. Synthesis, 57(48), 43-48 (2011)

5. Van de Sompel, H., Lagoze, C.: The Santa Fe Convention of the Open Archives Initiative. D-lib Magazine, 6 (2) (2000)

6. Van de Sompel, H.: The Implementation of the Berlin Declaration on Open Access. D-lib Magazine, 11 (6) (2000)

7. The open archives initiative protocol for metadata harvesting, version 2.0. https://www.openarchives.org/OAI/openarchivesprotocol.html (2017)

8. OAI-PMH Data Provider 2.0 (Internals) - DSpace 6.x Documentation - DuraSpace Wik, Wiki.duraspace.org, https://wiki.duraspace.org/pages/viewpage.action?pageId=68064778 (2017)

9. OAI 2.0 Request Results, https://eprints.soton.ac.uk/cgi/oai2?verb=Identify (2017)

10. OPUS 4 Entwicklung. http://www.opus-repository.org/devdoc/ (2017)

11. Recursos educativos abiertos | Organización de las Naciones Unidas para la Educación, la Ciencia y la Cultura, Comunicación e información. http://www.unesco.org/new/es /communication-and-information/access-to-knowledge/open-educational-resources/ (2017)

12. Medina-Ramírez, R., Galindo Durán, C., García-Cué, J.: Hacia una gestión semántica, masiva, abierta y vinculada de conocimiento y recursos educativos. In Tópicos introductorios a la gestión del conocimiento, Ediciones de la noche, 103-125, México (2016)

13. Gertrudis-Casado, M., Gértrudix-Barrio, M., Álvarez-García, S.: Professional Information Skills and Open Data. Challenges for Citizen Empowerment and Social Change. Comunicar, 47, http://dx.doi.org/10.3916/C47-2016-04 (2016)

14. Aguirre, S., Quemada, J., SalvachuaJ.: Mediadores e Interoperabilidad en Elearning. V Conferencia Internacional Anual sobre educación, capacitación profesional y tecnologías de la información. Barcelona, España (2004)

15. Ibert, B., Silva, E., Soares, E.: A computational model for developing semantic web-based educational systems. Knowledge-Based Systems, 22 (4), 302-315. https://doi.org/10.1016/ j.knosys.2009.02.012 (2009)

16. Arruti Gómez, A.: Analyzing and Producing Educational Resources for Didactalia.NET: A PilotProject Launched atthe University of Deusto (Spain Learners from Primary Education Degree). 8th International Technology, Education and Development Conference, Valencia, Spain (2014)

17. PROCOMÚN: Red de Recursos Educativos Abiertos, http://educalab.es/recursos/ procomun (2017)

18. Abele, A., McCrae, J.: The Linking Open Data cloud diagram, Lod-cloud.net, http://lodcloud.net/ (2017)

19. Medina Nieto, M., Sanchez, J., Cervantes, O., Benitez, A., De la Calleja, A.: LOD4AIR: A strategy to produce and consume linked open data from OAI-PMH repositories. International Conference on Electronics, Communications and Computers, CONIELECOMP, Puebla, Mexico (2017)

20. Red Mexicana de Repositorios Institucionales, http://www.remeri.org.mx/portal /index.html (2017) 
21. LA Referencia Web Site, http://lareferencia.redclara.net/rfr/ (2017)

22. Estrategia de acceso abierto a la información científica, tecnológica y de Innovación Repositorios Institucionales. Términos de referencia para desarrollar los repositorios institucionales de acceso abierto a la información científica, tecnológica y de innovación, CONACYT, $\quad$ http://www.conacyt.gob.mx/index.php/el-conacyt/convocatorias-yresultados-conacyt/convocatorias-direccion-adjunta-de-planeacion-y-

evaluacion/convocatoria-2015-para-desarrollar-los-repositorios-institucionales-de-accesoabierto-a-la-informacion-cientifica-tecnologica-y-de-innovacion/10724-terminos-dereferencia-repositorios-institucionales-2015/file (2017)

23. Documento del diagnóstico nacional de repositorios institucionales en la IES mexicanas mediante una muestra representativa, REMERI, http://www.remeri.org.mx/portal /img/documentos/Anexo3.pdf?iframe=true \&width=100\%\&height=100\% (2017)

24. DCMI Home: Dublin Core® Metadata Initiative (DCMI), http://dublincore.org/ (2017)

25. Frade Rubio, L.: Planeación por competencias. Inteligencia Educativa (2009)

26. Noy, N., McGuinness, D.: Ontology Development 101: A Guide to Creating Your First Ontology. Stanford Knowledge Systems Laboratory Technical Report KSL-01-05 and Stanford Medical Informatics Technical Report SMI-2001-0880 (2001)

27. Cervantes, H., Kazman, R.: Designing Software Architectures. A Practical Approach. Addison-Wesley (2016)

28. Díaz, J., Schiavoni1, A., Amadeo, P., Osorio, A., Pietroboni, M., Pagano, M.: Integrando un Repositorio Digital con un Sistema de Gestión de Bibliotecas a través de OAI-PMH. XVII Workshop de Investigadores en Ciencias de la Computación, Salta (2015)

29. González Castañón, M.: Evaluación de software educativo: orientaciones para su uso pedagógico. http://www.tecnoedu.net/lecturas/materiales/lectura27.pdf (2017)

30. Rodriguez, A. P., Dominguez, E. L, Velazquez, H., M. Nieto, M. A.: Usability Assessment of Mobile Learning Objects by High School Learners. IEEE Latin America Transactions 14(2), 1044-1049 (2016) 